\title{
WEIGHING THE OPTIONS: A LEGAL APPROACH TO CHILDHOOD OBESITY
}

\section{Jonathan Mark Solomon*}

Growing childhood obesity rates are increasingly putting the lives of Canadian children at risk. Using schools as the foundation for tackling childhood obesity is significantly more achievable than attempting to place blanket measures that intrude into Canadian homes. Measures should be taken to address childhood obesity by promoting healthy eating, education and exercise. Yet it is important to recognise obesity both as a medical and as a pyschosocial problem in order to construct these preventative policies: by doing so we can begin to understand the potential challenges such as stigma along with negative exogenous influences in the home and as consumers.

Les taux croissants d'obésité juvénile montrent que les enfants canadiens sont de plus en plus exposés à un risque pour leur santé. Il est beaucoup plus réaliste de passer par les écoles pour s'attaquer au problème de l'obésité juvénile que de tenter de mettre en ouvre des mesures générales qui constituent une ingérence dans les foyers canadiens. Il faut prendre des mesures pour lutter contre l'obésité juvénile en encourageant les saines habitudes alimentaires, l'éducation et l'exercice. Il importe aussi de reconnaître l'obésité comme un problème d'ordre tant médical que psychosocial avant d'élaborer ces politiques préventives : de cette façon, nous pourrons commencer à comprendre les difficultés possibles telles que l'ostracisme et les influences exogènes négatives dans les foyers et comme consommateurs.

\section{INTRODUCTION}

The prevalence of overweightness and obesity among Canadians is a pressing concern for public health. This is especially the case for obesity rates among children. Numerous international health organizations and public health authorities note the importance of addressing the obesity epidemic to ensure that current rates are brought under control. To this end, it is often suggested that preventive efforts be directed at children. Even if one were to accept the spurious but oft made argument that obesity is a matter of self-regulation, this argument would not apply in the context of children, as children are at the behest of their parents, relatives, and numerous other adults that regulate their day to day lives. Consequently, it would be insufficient to focus preventive measures on educating children about selfregulation; instead, a tailored policy is required to address childhood obesity, as interventions aimed at

(Barrister) B.A. Hons (Oxon), LL.M.; C.I.H.R. Fellow in Health Law, Ethics and Policy 2013/14; Scace Graduate Fellow 2013/14; Lord Denning Scholar, Lincoln's Inn. I would like to thank Jacob Shelley for his tremendous support with the structure, preparation and polishing of this paper; Gabrielle Gleeson for her support and help throughout the writing process; Richard Solomon for his assistance in reviewing the paper in its final stages of editing; Canadian Institute of Health Research for their contribution through my Canadian Institute of Health Research Fellowship in Health Law, Ethics and Policy, in particular in relation to funding and the opportunity to present this paper at the annual colloquium; Scace Family for their contribution to the Scace Graduate Fellowship at the University of Toronto. 
changing children's behaviours will ultimately be unsuccessful. Instead, I argue it is more plausible to implement preventive measures in schools, particularly measures aimed at healthy eating, nutritional education, and increased physical exercise and weight surveillance in schools. In part two I explain the reasons why intervention for childhood obesity is necessary. In part three, I frame the obesity question. In part four, I explain the focus on preventative measures. In part five, I explain that because of the mechanisms inherent within its structure and its role in influencing children, schools provide the best forum for implementing schoolbased intervention. In part six I discuss and dismiss other forums for intervention. In part seven, I address the challenges facing schoolbased interventions including the impact of stigma. In part eight, I systematically analyze each potential intervention and assess its suitability in Canadian Schools. Throughout this discussion I recognize the existence of exogenous factors, such as the home environment and the influence of Big Food, ${ }^{1}$ that contribute to the obesity problem, but appreciate that the obesity problem is societal and schools offer a forum for intervention which bypasses the challenges of these exogenous areas. Finally, I conclude that the most appropriate interventions in Canadian schools are educational intervention and the improvement of the nutritional environment in schools.

\section{REASONS FOR ACTING}

In this section, I will explain why obesity is specifically a problem for children and why intervention is required. A major problem for children is their lack of knowledge about how to eat properly coupled with their inability to take proper care of themselves (without the appropriate guidance or supervision). In effect children "are a vulnerable population subject to adult authority." 2 In fact the vulnerability of children is recognized in many state, national and international laws. ${ }^{3}$ For example, the United Nations Convention on the Rights of the Child ${ }^{4}$ has three relevant articles. Article 3 states that "in all actions concerning children, whether undertaken by public or private social welfare institutions, courts of law, administrative authorities or legislative bodies, the best interests of the children shall be a primary consideration." Article 6 acknowledges, "State Parties recognize that every child has the inherent right to life. State Parties shall ensure to the maximum extent possible the survival and development of the child." ${ }^{6}$ Finally, Article 24 provides inter alia, that children have the right to the highest attainable standard of health, to necessary medical assistance and health care and to the provision of adequate nutritious food. ${ }^{7}$ It is appreciated that special protection is required to safeguard the interests of such a vulnerable sector of society. The underlying principles of each of these rights underpin the fundamental moral fabric and obligations of society. In light of them, arguably, it is contrary to the altruistic nature of human kind and international law to allow the childhood obesity epidemic to remain unchecked.

The term Big Food is used to describe corporate and unhealthy food including, but not limited to, candy, soda and fast food.

2 Keeley J Pratt \&Annette G Greer, "Debating Parental Responsibility for Childhood Obesity: Ethical and Legal Considerations" (2012) 7:3 Bariatric Nursing and Surgical Patient Care 146 at 147.

Ibid.

4 Convention on the Rights of the Child, 20 November 1989, UNTS 1577.

Ibid at article 3.

$6 \quad$ Ibid at article 6.

7 Ibid at article 24. 
There are dangers inherent in living with obesity and these risks require intervention. "Scientific research strongly suggests that childhood obesity is largely attributable to genetic and environmental factors that are beyond the reach of individual choice or control." ${ }^{\prime 8}$ Scientists often refer to our nutritional environment as obesigneic, or as Wiley observes, "in simple terms that 'if you go with the flow you'll get fat." "' 9 Therefore, childhood obesity is a societal problem and it is the responsibility of the current generations of adults to help guide future generations, as vulnerable members of the population, towards healthy lives.

\section{FRAMING THE ISSUE}

Obesity is a problem that resonates through Canada and globally. In 2005, 59\% of Canadians were either overweight or obese and this number is still increasing. ${ }^{10}$ In $2007,29 \%$ of adolescents and children in Canada had unhealthy weights ${ }^{11}$ and by $201035 \%$ of children in Canada were deemed to be overweight or obese. $^{12}$ In $2011,21 \%$ of US children between the ages of 2 and 5 were obese $^{13}$ and worldwide more than 40 million children under the age of 5 were overweight. ${ }^{14}$

The World Health Organization [WHO] defines overweightness and obesity as individuals with a BMI that is greater than or equal to 25 or 30 , respectively. ${ }^{15}$ An individual is considered morbidly obese if they have a BMI above 40. Patel provides an anecdotal contextualization of this definition, noting that "a morbidly obese person usually weighs twice more than he or she should or $50-100 \%$ over the ideal weight." ${ }^{\text {"16 }}$ Children are not immune to being morbidly obese: in 2011, 21\% of US children between the ages of 2 and 5 were obese. ${ }^{17}$ And in extreme cases, children have been found to weigh in excess of $650 \mathrm{lbs}^{18}$ (over 3.5 times the average weight of men in Canada in 2008). ${ }^{19}$

$8 \quad$ Lindsay Wiley, "No Body Left Behind: Re-Orienting School Based-Childhood Obesity Interventions" (2013) 5:97 Duke Forum For Law \& Social Change 97 at 101.

$9 \quad$ Ibid at 101; Kerry Trueman, "The Terrifying Truth About America's Obesity Epidemic", (11 May 2012), online: ALTERNET $<$ http://www.altemet.org/health/155398/the-terrifying-truth about america's-obesity-epide mic?page $=$ entire $>$.

10 Statistics Canada, "Measured Obesity. Adult Obesity in Canada: Measured Height and Weight", No. 1, catalogue no: 82-620-MWE2005001 by Michael Tjepkema (Ottawa: StatCan, 6 July 2005) at Table 1.

11 Childhood Obesity Foundation, "Statistics", online: Childhood Obesity Foundation $<$ http://www.childhoodobesityfoundation.ca/index.php>.

12 Nola M Ries \& Barbara von Tigerstrom, "Legal Interventions to Address Obesity: Assessing the State of the Law in Canada" (2010-2011) 43:2 UBC L Rev 361 at 361.

13 WA Bogart, "Law as a Tool in "The War on Obesity": Useful Interventions, Maybe, But, First, What's the Problem" (2013) 41:1JL Med \& Ethics 28 at 30.

14 Body mass index [BMI] is a simple index of weight-for-height that is commonly used to classify overweight and obesity in adults. It is defined as a person's weight in kilograms divided by the square of his height in meters $(\mathrm{kg} / \mathrm{m} 2)$; World Health Organization, "Obesity and Overweight: Fact Sheet" (March 2013), online: World Health Organization $<$ http://www.who.int/mediacentre/factsheets/fs311/en/> [WHO Website].

15 Ibid.

16 Deena Patel, "Super-Sized Kids: Using the Law to Combat Morbid Obesity in Children"(2005) 43:1 Family Court Review 164 at 165.

17 Bogart, supra note 13.

18 The case of Christina Corrigan, a 13-year-old girl weighing over 680lbs; See Patel, supra note 16 at 170., 
Importantly, an individual can be overweight or obese and still be healthy, a point the Fat Rights movement and groups such as Health at Every Size like to point out. ${ }^{20}$ However, morbid obesity is not a matter of 'puppy fat', but concerns individuals that exceed all recommended healthy weight guidelines. Individuals that exceed healthy weight guidelines are at a significantly heightened risk of medical and psychosocial problems.

These statistics demonstrate increasing prevalence of obesity in Canada and they serve as a warning for the rapid exacerbation of obesity in adults: today's children are tomorrow's adults and without a proper understanding of healthy eating and healthy weights, an increasing amount of poor eating habits and poor health will be passed on from generation to generation. Without taking significant action at the source of this problem the scope for escalation is vast and the potential snowball effect insurmountable.

\section{A. As a Medical Problem}

Obesity can have serious ramifications on a person's health. Obese individuals are at an increased risk to suffer from a number of related comorbidities. For example, obese individuals are at an increased risk of heart disease, cancer and strokes. ${ }^{21}$ The likelihood of related comorbidities increases with gains in an individual's weight. ${ }^{22}$ The problem is related both to the increased strain on the body as well as a general trend in the amount of exercise conducted by individuals who are overweight. ${ }^{23}$ In effect, a vicious circle can transpire continually contributing to the exacerbation of the problem.

Related illnesses have a particularly worrying effect on children as obese children face heightened risks. One major consequence of weight-related problems is that "children are now facing the onset of weight-related disease that typically affected people over age forty a generation ago." 24 A prime example of this can be seen in the United States, where the Centers of Disease Control (CDC) estimated that 1 in 3 American children born in 2000 will develop diabetes, noting that "children under the age of 10 years of age are already developing type 2 diabetes, which is primarily seen in adults." ${ }^{.25}$ Research has shown that "obesity during adolescence has been associated with an increased risk of blood glucose levels indicative of a high risk of developing diabetes in the future." ${ }^{\prime 26}$ The increased prevalence of these conditions at a much younger age can have catastrophic consequences for the health of the individuals involved as well as the overall health care system, as the cumulative health costs put further strains on already stretched health care budgets.

19 Statistics Canada, Margot Shields, Sarah Gorber, Ian Janssen and Mark Tremblay, "Bias in self-reported estimates of obesity in Canadian Health Surveys: An update on correction equations for adults" by Margot Shields et al, 22:3 Health Reports, catalogue no: 82-003 (StatCan, August 2011) at 4.

22 Ibid; Research has shown that adults with obesity and overweightness may die up to 3 to 7 years earlier than their healthy weight counterparts; A Peeters et al, "Obesity in adulthood and its consequences for life expectancy: A life table analysis" (2003) 138:1 Annals of Internal Medicine 24.

23 Nell Card, "Exercise Advice for Overweight People" The Guardian (15 August 2011) online: <http://www.theguardian.com/lifeandstyle/2011/aug/15/exercise-advice-overweight-people>.

24 Adam Larson, "The American Childhood Obesity Epidemic: Probable Causes and the Legislative and Judicial Responses" (2008) 28:1 Child Legal Rts J 1 at 1.

25 National Sleep Foundation, "Obesity and Sleep", online: National Sleep Foundation $<$ http://www.sleepfoundation.org $>$.

26 See Wiley, supra note 8 at 103. 


\section{B. As a Psychosocial Problem}

Although it has been considered less often than the more obvious dangers posed by the potential medical consequences of obesity, there is growing awareness of the equally troubling psychosocial problems inherent with being overweight or obese. In 2001, Latner and Stunkard replicated a study from 1961 that examined stigma and found that the level of stigma shown towards heavier individuals has increased over the last half century. ${ }^{27}$ Further to the personal condemnation that many overweight individuals suffer, there is the additional burden of societal disapproval. Children do not escape this disapproval.

Pratt and Greer argue that "children who struggle with weight may also struggle with psychosocial comorbidities including: anxiety, bullying and teasing, depression poor self-esteem, and social isolation." ${ }^{28}$ In addition to the psychological problems that children can suffer as a result of selfreflection upon their own bodies, the consequences of such feelings are often exacerbated by "social bias and harassment inflicted upon that child by others." 29 In a society that is becoming increasingly aware of mental health issues, the potential influence and consequences that weight-related social stigma could have on mental health should not be ignored. ${ }^{30}$ Similar to those of medical comorbidities, the consequences of weight-related psychosocial comorbidities should not be underestimated. Obese individuals that suffer from such conditions contribute to increased societal healthcare costs and in the long-term, due to illness and lack of stamina, do not contribute to societal productivity by missing days from work or being unable to participate in certain tasks. ${ }^{31}$

\section{PREVENTATIVE POLICIES}

For the purpose of this discussion, I contend that the underlying goal of any obesity policy should be obesity prevention. Obesity policies often have a myriad of goals, including weight loss, the general improvement of health, and combatting stigma. While each of these goals has merit, the focus on preventing obesity in the first place removes the need to implement policies for weight loss or the improvement of weight-related health. By preventing and reducing the prevalence of obesity, general health will be improved and the need for weight loss removed. Moreover, weight prevention is a more plausible policy goal than weight loss because "95\% of obese people, of those able to lose weight gain it all back within five years." ${ }^{2}$ On this basis, preventing individuals from gaining the weight in the first place is to take the path of least resistance.

27 Janet D Latner \& Albert J Stunkard, “Getting Worse: The Stigmatization of Obese Children” (2003) Obesity Research 11:3 at 1. Article recognizes that the stigmatization of children has increased since 1961 - this is demonstrated by replicating a 1961 study of stigma in childhood obesity to see what effect prevalence has on the issue.

28 See Pratt \& Greer, supra note 2 at147.

29 See Wiley, supra note 8 at 105.

30 The increasing awareness of mental health can be demonstrated by the increasing prevalence of organizations such as the Canadian Mental Health Commission, online < http://www.mentalhealthcommission.ca/English/who-we-are $>$, and the Canadian Mental Health Association < http://www.cmha.ca/>.

31 Joanne Ikeda, Patricia Crawford \& Gail Woodward-Lopez, "BMI Screening in Schools: Helpful or harmful?” (2006) 21:6 Health Education Research 761 at 766.

32 Deborah Rhode, The Beauty Bias: The Injustice of Appearance in Life and Law (New York: Oxford University Press, 2010) at 105; See Bogart, supra note 13. 
Even with the focus on prevention, I acknowledge the importance of tackling obesity stigma when proposing policies. Given the stigma inherent in weight-related interventions, many measures will have a related and often predictable impact (either increase or decrease) on stigma. On this basis, I assess each proposed intervention on whether it will increase or decrease related stigma and use this to help determine their respective benefits.

\section{A. Preventative Policies for Childhood Obesity}

For many of the reasons explained above, childhood obesity poses a significant long-term danger to society. However, the increased prevalence of childhood obesity and its consequences for the long-term development of society's adults poses an intriguing opportunity for preventative measures. If obesity can be prevented in children, this is likely to result in a reduction in future rates of overweight and obesity in adults.

Research has shown that the "number of fat cells an individual develops tends to be determined in the first few years of life." ${ }^{33}$ The development of fat cells is "dependent on genetic factors and eating habits." 34 Although some might argue that obesity is genetic and thus cannot be prevented, the dual cause of the development of fat cells demonstrates that for many, the problem is not solely bad genes. By failing to ensure that children are healthy, and by allowing them to develop high levels of fat cells, a dangerous precedent is set that may put children on the path to morbid obesity, and towards long-term weight-related ill health. Yet, addressing the issues for children provides both an immediate impact in reducing the effect of medical and psychosocial comorbidities while helping to shift cultural norms and perspectives on obesity.

The potential consequences of failing to address the prevalence of obesity in Canadian children could be catastrophic to society on the whole. A recent study in the UK demonstrated that the worldwide healthcare cost of obesity is equivalent to the cost of smoking. ${ }^{35}$ A report by the McKinsey Global Institute estimated that the global cost of obesity is $£ 2$ trillion in $2012 .{ }^{36}$ They found that $30 \%$ of the world's population, approximately 2.1 billion people,were obese or overweight. ${ }^{37}$ The report further estimated that by 2030 , half of the world's population could be deemed overweight or obese. ${ }^{38}$ The report discussed the "steep economic toll" ${ }^{39}$ of obesity, highlighting the financial costs of increased demands on the healthcare system and an overall reduction in societal output and lost working days. ${ }^{40}$ The report also contrasted the potential costs the United Kingdom might face if it failed to address the obesity problem with the potential savings (if the correct measures were taken) estimating as long-term

\footnotetext{
33 Amanda Clark, "The Role of the School Nurse in Tackling Childhood Obesity" (8 June 2004), 100:23 at 1, online: The Nursing Times <http://www.nursingtimes.net>.

34 Ibid.

35 McKinsey Global Institute, “Overcoming Obesity: An initial economic analysis” (November 2014) at 1, online: < http://www.mckinsey.com/insights/economic_studies/how_the_world_could_better_fight_obesity>.

36 Ibid at 2, Exhibit E1.

37 Ibid at 14.

38 Ibid at viii.

39 Hugh Pym, “Obesity costing same as smoking”, BBC News (14 November 2014) online: < http://www.bbc.co.uk/news/health-30122015>.

40 Ibid.
} 
saving of $£ 760 \mathrm{~m}$ per year for the National Health Service. ${ }^{41}$ Arguably, proportionate savings could be realized in Canada if appropriate, effective and extensive measures are put in place before the crisis escalates out of control.

One aspect addressed in the McKinsey report is the assertion that measures that take into account the societal nature of the problem, and that do not focus on the responsibility of individuals, are required to tackle the problem. ${ }^{42}$ Shelley, who argues that the debate about obesity prevention suffers from a cacophony of information and has become over politicized, draws out a similar sentiment. ${ }^{43} \mathrm{He}$ emphasizes that "obesity is the outcome and not the cause" 44 and that finding a solution requires acknowledging the systemic nature of the problem. ${ }^{45}$ Shelley notes the importance of framing, ${ }^{46}$ and proposes the terminology of 'caloric overconsumption' to depart from traditional 'energy output' model for considering obesity. This approach facilitates an understanding of food environments as a risk to health, often beyond individual control. ${ }^{47}$ Such a focus is particularly useful in tackling childhood obesity: often risks are beyond an individual child's control.

Children suffer from the influences of their nutritional environments, whether that be their home environment, the prevalence of vending machines, access to big food brands or the food served in schools. The responsibility is not - and should not be - contextualized as that of the child. Despite allegations that obesity is a consequence of poor self-regulation, it would be erroneous to consider such concerns in relation to children. Rather, adults (parents, guardians or schools) generally supervise a child's access to food. As Patel cheekily observes: "Do little kids steal their parent's car keys and drive themselves to McDonald's? No." ${ }^{, 8}$ Young children that are overweight bear no personal responsibility; rather, it is the direct consequence of the child's nutritional and social environment. A five-year old does not have the cognitive ability to weigh the pros and cons of eating particular foods or to determine the appropriate nutritional input. Taking into account Shelley's analysis, which suggests the use of measures that recognize the influence of the food environment, a solution to the problem of childhood obesity requires that responsibility for children be taken by supervising adults, and this includes schools.

5. Schools provide an appropriate venue for the implementation of obesity prevention interventions

\section{A. Role in Child's Life}

Schools, arguably, are second only to the home as the biggest influence on a child. ${ }^{49}$ Parents, obviously, are the primary purchasing agents for the majority of a child's nutritional resources; however,

\footnotetext{
41 Ibid.

42 See McKinsey Global Institute, supra note 35 at viii.

43 Jacob Shelley, "Addressing the Policy Cacophony does not Require More Evidence: An Argument for Reframing Obesity as Caloric Overconsumption” (2012) 12:1042 BMC Public Health at 3.

44 Ibid.

45 Ibid at 4

46 A 'framing effect' is how an issue is presented results in large changes of opinion. Ibid at 3.

$47 \quad$ Ibid at 4

48 See Patel, supra note 16 at 164.

49 See Pratt \& Greer, supra note 2 at 146.
} 
children from age 4 to 16 spend $50 \%$ of their waking hours in the educational system $^{50}$ where they consume a "significant portion of their daily caloric intake."

Not only do children spend a lot of time in schools, the individuals that they come into contact at school can have a significant influence on them. Two significant factors of influence in the school are a child's teachers and his/her peers. As discussed, a major cause of the increasing prevalence of overweight and obesity is that children are not necessarily capable of making decisions about the types of food to eat or how to live healthier lifestyles. By encouraging a cultural shift in the perceptions towards healthy eating and obesity within schools, the right information can be provided to children, teachers and peers. An effective melting pot of progressive information can then be shared between peers and teachers, which in turn can assist in influencing children to make the correct nutritional decisions in life.

There are a vast number of potential interventions that could be implemented in schools. Each type of intervention will be discussed more extensively below but as way of a brief overview, schools have a supervisory role over the children. Such supervision could extend to regulating what food is allowed in school lunch boxes, what other children bring to school, ${ }^{52}$ what food is available in school canteens, the availability of vending machines, and the broader food environment surrounding a school. Additionally, there is also potential to use the school's curriculum as a venue to educate children in the benefits of eating healthy, thereby helping prevent obesity and improving the weight-related health of children.

\section{B. Public Support}

There is widespread public support for using schools to implement obesity prevention strategies. Research has shown that $65 \%$ of parents believe schools should play a significant role in reducing childhood obesity, ${ }^{53}$ and $83 \%$ of adults believe that "public schools should do more." ${ }^{, 54}$ As alluded to by Shelley, the whole topic of obesity has become politically polarized ${ }^{55}$ yet a significant majority remains in support of school intervention. Given that any potential intervention will require passing legislation, public support helps to limit any potential barriers in the minds of politicians and provides an opportunity for political opportunism in favour of obesity prevention.

\section{POTENTIAL EFFECTIVENESS OF OTHER VENUES}

\section{A. Homes}

Despite having a huge influence on the lives of children, the implementation of measures would look very different in the home compared with such measures in schools. Home-based measures would need to focus on curtailing the presence of foods with poor nutritional value. An unavoidable consequence of any measure taken to regulate a child's home-based nutritional environment is the impact on any adults

$50 \quad$ Ibid at 147.

51 Victoria Brescoll, Rogan Kersh \& Kelly Brownell, "Assessing the Feasibility and Impact of Federal Childhood Obesity Policies" (2008) 615:1 The Annals of the American Academy of Political and Social Science 178 at 180.

52 R H Coase, "The Problem of Social Cost" (1960) 3 JL \& Econ 1.

53 Jonathan Kropski, Paul Keckley \& Gordon Jensen, "School-based Obesity Prevention Programs: An Evidence-Based Review" (2008) 16:5 Obesity 1009 at 1009.

54 See Brescoll, Kersh \& Brownell, supra note 51 at 181.

55 See Shelley, supra note 43 at 3. 
in the home. Given the intrusive nature of such measures, home-based interventions are controversial and unlikely to be adopted by politicians; the likelihood of any such measures ever getting passed by any sitting government is doubtful. Home-based policies require dual considerations: firstly an examination what measures can be implemented and secondly, whether any of these measures can be justified despite their intrusion on Canadian adults.

An extremely intrusive home-based measure is the regulation of the entire nutritional market: limiting the purchasing choices of everyone. A less-intrusive option is the use of public health 'nudges, ${ }^{56}$ which have the aim of guiding adults towards making healthier choices for the sake of children. Regulation involves restricting purchasing choices, while nudges consist of interventions to "gently steer individual choices in welfare-enhancing directions without imposing any significant limit on available choices." 57 Nonetheless, both approaches ultimately curtail the autonomy of consumers, and can rightly be descripted as paternalistic given that they impose system wide restrictions on individual choices. This is especially the case for regulation or legislation, which is far more heavy handed than a nudge. Paternalism can be defined the "protection of competent adults irrespective of their expressed desires." 58 Even if these measures were implemented with the aim of protecting children, both would still impinge on the liberty of competent adults. The intrusiveness of regulating nutrition is compounded by the fact that to ensure any impact on childhood obesity rates, these types of policies would require widespread application and implementation. Consequently, they would impact adults, including those that have no children to influence. Limiting adult autonomy on such a vast scale flies in the face of liberty, as protected by the Canadian Charter of Rights and Freedoms. ${ }^{59}$

Despite the breadth of the obesity epidemic, home-based regulatory measures will likely struggle to satisfy the Oakes test. ${ }^{60}$ The Oakes decisions confirmed that not all of the rights and freedoms protected by the Charter are absolute, and that limitations may be necessary in some circumstances to achieve collective goals of fundamental importance. To determine if such restriction is necessary the case put forward a two-stage test. First, considering whether the right is pressing and substantial in a free and democratic society and secondly, whether the restriction is proportionate to the perceived goal ${ }^{61}$. While, it is conceivable that the objective of tackling childhood obesity is sufficiently important to warrant the overriding of a Charter right, neither blanket measures of regulation nor extensive nudging are reasonably proportional. Regulating or nudging the purchasing autonomy of vast portions of the population is undoubtedly arbitrary and unfair, particularly given that many individuals impacted would have little to no influence over children. Neither of these proposed measures are directly or fairly connected to the objective of addressing childhood obesity. Rather, each measure extensively impairs an individual's right to liberty. To be achieved, measures must be less intrusive or significantly more explicitly directed towards addressing childhood-obesity. In the unlikely event that politicians did adopt

56 Jean-Frederick Menard, “A 'Nudge' for Public Health Ethics: Libertarian Paternalism as a Framework for Ethical Analysis of Public Health Interventions?” (2010) 3:3 Public Health Ethics 229 at 233.

57 Ibid.

58 L O Gostin \& K G Gostin, “A Broader Liberty: JS Mill, Paternalism and the Public's Health” (2009) 123 Public Health 214 at 214.

59 Canadian Charter of Rights and Freedoms, s 7, Part I of the Constitution Act, 1982, being Schedule B to the Canada Act, 1982 (UK), 1982, c 11.

$60 \quad R v$ Oakes, [1986] 1 SCR 103, 1986 CanLII 46.

61 Ibid at 70 
an approach to obesity prevention that focused on home environments, such measures will likely be deemed unconstitutional on the basis of this Oakes analysis.

Less intrusive measures aimed at the home environment are likely to have limited effectiveness. At the very most, governments can make recommendations for living healthy lifestyles or provide fiscal incentives, such as tax exemptions. A significant problem with tax exemptions ${ }^{62}$ is their inability to contribute to poor income families: if parents cannot afford to buy a child's hockey stick, it is irrelevant if that stick can be bought without paying tax. This problem remains despite the Harper government's initiative to increase the extent of the tax exemption: the only homes that benefit from such an exemption are those that can afford to pay the base price of the hockey stick. ${ }^{63}$ Even promoting exercise in the home appears devoid of viable options.

In summary, even on a prima facie analysis, introducing preventative policies in the home environment is both impracticable and likely to face significant resistance from the public.

\section{B. Big Food}

It would erroneous not to recognize other exogenous factors, primarily advertising, competitor foods and the influence of peers, which contribute to a child's nutritional environment. "Food manufacturers and marketers have long advertised [processed] foods specifically to children with the hopes that children influence their parents purchasing decisions." ${ }^{26}$ There is a significant debate surrounding the influence of advertising and competitor foods in contributing significantly to the obesity problem. ${ }^{65}$ The ubiquitous nature of advertising and the availability of processed foods exacerbate the problem of peer influences and heavily contribute to the infiltration of unhealthy foods into the nutritional environments of children. ${ }^{66}$

There are two factors that must be considered when determining whether regulation of Big Food offers an alternative forum within which to tackle childhood obesity. The first is merely to re-emphasize the importance of the distinction between the US and Canada. While the influences of Big Food is a problem in Canada, the prevalence and influence of big corporations is not as significant as it is in the US. $^{67}$ Secondly, it should be recognized that despite the difference between the US and Canada, corporations still hold a significant amount of influence over policy making in Canada. Any attempt to ban or regulate a child's access to food or to regulate the substance put into such foods will be met with significant resistance.

62 Canada Revenue Agency, “Children's Fitness Amount, online: Canada Revenue Agency" < http://www.craarc.gc.ca/fitness/>.

63 Canadian Press, Jason Fekete \& Postmedia News, "Stephen Harper unveils income splitting tax break for Canadian families with children under 18", National Post (30 October 2014), online: National Post < http://news.nationalpost.com/2014/10/30/stephen-harper-unveils-income-splitting-tax-break-for-canadian-families-with-children-under$18 />$.

64 See Larson, supra note 24 at page 1.

65 Jess Alderman et al, "Application of Law to the Childhood Obesity Epidemic" (2007) 35:1 JL Med\& Ethics 90 at 97.

66 Ibid at 93

67 Jeff Beer, "Fast food: Invasion of the burger joints" Canadian Business (9 November 2012), online: <http://www.canadianbusiness.com/lifestyle/fast-food-invasion-of-the-burger-joints/>; American businesses, especially those focusing on big food are expanding to Canada in the hope of maximizing profits. There is a significantly greater number of such companies in the US including "Denver, Colo.-based chains Chipotle Mexican Grill and Smashburger; Minneapolis, Minn.-based Buffalo Wild Wings; Arizona's P.F. Chang's; and Carl's Jr. from California.” 
Passing any banning or regulative measures will face significant problems at the implementation stage. This controversy will likely resemble the resistance put forward by tobacco companies following the federal Tobacco Products and Control Act ${ }^{68}$ as seen in the case of RJR MacDonald Inc v Canada (Attorney General) ${ }^{69}$ In that instance, tobacco companies challenge the Act as ultra vires of government powers and in violation of section 2(b) of the Charter (freedom of expression) ${ }^{70}$ The regulation of big food poses a direct threat the profits of extremely rich and influential companies and similar resistance will be posed. Nonetheless, it should be noted that while tobacco companies rallied in resistance, reform and regulation were eventually achieved. ${ }^{71}$

Given the vast number of products manufactured by Big Food available in stores across Canada, and the ease with which parents or children can purchase such products, Big Food resistance raises a significant barrier to any form of regulation. It is not practical to impose an age limit on the purchase of such products, and any such attempt to do so would undoubtedly be met with significant public opposition and be very difficult to enforce. Therefore, the only potential basis for regulating a child's access to such food would be to limit the availability of these items by restricting the trade of the companies that make them. Such an approach will definitely be met with considerable opposition.

A lesson about how the food industry might respond to obesity prevention initiatives can be taken from the Sugar Association's (representing the US sugar industries) extensive critique of WHO guidelines on healthy eating "suggesting that sugar should account for no more than 10 percent of a healthy diet." 72 The sugar industry in the US threatened "to bring the World Health Organization to its knees by demanding that Congress end its funding unless the WHO" scrapped guidelines on healthy eating. ${ }^{73}$ Many of these types of industry-backed organizations use "strong-arm tactic" including generation coalitions with hundreds of large companies such as Coca-Cola and Pepsico. ${ }^{74}$ The underlying problem is that "food systems are not driven to deliver optimal human diets but to maximize profits. ${ }^{, 75}$ If initiatives are proposed that will threaten the stability of the profit stream of big companies, they will undoubtedly reject such efforts in a manner similar to how the Sugar Association responded to the WHO's $10 \%$ sugar guideline. In fact, a potential reason for the lack of substantive policies to address obesity thus far may be the influence of Big Food companies who wield enormous influence over national politics. ${ }^{76}$ Expressly or impliedly, these companies make it extremely difficult to levy effective food restrictions on a large scale. On this basis, any attempt at taxation or regulation is likely to fail. Regulation of the tobacco industry faced similar barriers. While it is not impossible to enact regulation

68

69

70

71

72

S Boseley, "Political Context of the World Health Organization: Sugar Industry Threatens to Scupper the WHO" (2003) International Journal of Health Services: Planning, Administration, Evaluation 831. The, article is an adaptation of Sarah Bosley, "Sugar Industry Threatens to Scupper WHO", The Guardian, (21 April 2003) online: < http://www.theguardian.com/society/2003/apr/21/usnews.food $>$.

73 Ibid at 831.

74 Ibid at 832 .

75 David Stuckler \& Marion Nestle, "Big Food, Food Systems and Global Health”, (2012) 9:6 PLOS Medicine at 1.

76 Ibid at 2 . 
and bring about change, as has happened in tobacco control, it will likely require a vast cultural shift in the public perception of the dangers of unhealthy foods, similar to the shift in public sentiment about smoking. ${ }^{77}$ Currently, such a cultural change has not occurred.

\section{THE CHALLENGES}

Traditional school-level obesity policies aim to promote healthy body weights among students, but often the overall aim of such policies becomes confused when analyzing the combination of prevention, weight reduction and reducing stigma while trying to focus on achievability. It is rare for policy makers to openly admit the lack of cohesion that often exists between preventative and curative policies when compared with policies that aim to reduce stigma. Nor do policy makers recognize the need for "a strategy of sufficient scale is needed as obesity is now reaching crisis proportions." 78 While interventions in schools, at home or against big corporations can be considered in isolation, there is inherent value in recognizing the potential of a comparative approach.

On this basis, legal interventions for tackling childhood obesity in Canadian schools face two significant and pressing challenges. The first is how to address concerns of stigma and the second is how school-based interventions required modification and/or collaboration to achieve the highest level of efficacy. These concerns will be considered in turn.

\section{A. Stigma}

When analyzing school interventions three things about obesity stigma need to be considered. Firstly, how prevalent is obesity stigma? Secondly, what is the impact of stigma among these obese children? Finally, how can school based interventions be implemented in such a way to address concerns about stigma?

The extent of stigma within the context of obesity is addressed by Puhl and Brownell who have identified that "obese persons are the last acceptable targets of discrimination." "79 Even within the medical sector, there is an aura of "discomfort, reluctance and dislike" towards obesity. ${ }^{80}$ A "study examined the attitudes about obese patients in health care professionals specializing in nutrition and found that $87 \%$ believe that obese people are indulgent, $74 \%$ believe that they have family problems, and $32 \%$ believe that they lack will power." 81 "Furthermore, $88 \%$ said that obesity was a form of compensation for lack of love or attention, and $70 \%$ attributed the cause to emotional problems." ${ }^{\prime \prime 2}$ Even within the medical field, the prevalence of obesity stigma demonstrates the barriers that individuals who suffer from overweightness and obesity face. Beyond the medical context, obesity stigma in the school context can be particular damaging to a child's development. "Peer rejection may be an overweight individuals' first challenge in the educational setting., ${ }^{, 3}$

Ibid at 1.

See McKinsey Global Institute, supra note 35 at 1, Executive Summary.

R Puhl \& KD Brownell, "Bias, Discrimination and Obesity" (2001) 9:12 Obesity Research 788 at 788.

Ibid at 792 .

81 LA Maiman et al,“Attitudes Toward Obesity and the Obese among Professionals” (1979) 74:3 Journal of the American Dietetic Association 331.

82 See Puhl \& Brownell, supra note 79 at 792.

83 Ibid at 795. 
Puhl and Brownell identify the psychological and social consequences of educational-related stigma. ${ }^{84}$ "A study of children 9 to 11 years of age reported that clinically overweight children had significantly lower self-esteem than non-overweight children" ${ }^{\prime 85}$ There is even evidence of anti-fat attitudes in preschool. ${ }^{86}$

Reflecting upon this pervasive bias against overweightness and obesity, any consideration of legal intervention must be cognitive of the potential stigma the policy may enforce. Any policy that has the potential to increase stigma, should be assessed on a proportionality test to determine whether the risked increase in stigma is counterbalanced and outweighed by the projected overweight and obesity preventative benefits.

\section{B. Assistance of Homes}

As previously discussed, homes serve as an unsuitable venue for legal intervention to tackle obesity, however, their influence remains as a challenge to any school-based intervention. A major problem of considering school-based interventions in isolation is the failure to take account of the influences of the home environment. Nutritional environments at home and the actions of parents can easily undermine any school-based measure. Healthy eating measures will be undermined if children can go home and consume cola and fast food; educational programmes are undermined by the habits and opinions of parents, and exercise programmes are damaged by sick notes and a failure to maintain exercise during holiday breaks.

The detrimental impacts of parents was demonstrated in a US study, which found that $80 \%$ of children are obese when at least one parent suffers from obesity, compared to only $10 \%$ when neither parent is obese ${ }^{87}$ Children learn from the nutritional and exercise habits of their parents and family. While school based intervention can serve as the foundation, it would be erroneous to ignore the home altogether. A 'portfolio of policies, ${ }^{88}$ or at the very minimum a policy that shows awareness of the influence of homes is required. In essence, the cooperation of the home environment is fundamental to the success of any school-based policy.

A major objective of a collaborative approach should be to ensure that parents are sufficiently informed to contribute to any school based intervention. This could potentially be achieved in a number of ways. For example, schools could encourage parents to actively participate in class assignments that require students to consider the healthiness of their home nutritional environment. Such an assignment would require parents to reflect upon their own purchases and their impact on their child's nutrition. Alternatively, schools could use weight-monitoring tools, ensuring that parents understand the realities of a child's weight and associated problems. Should surveillance be deemed a feasible intervention, a 'BMI report card' ${ }^{89}$ can be created, giving parents detailed information about their child's weight. This information might be especially important, given that evidence suggests that parents with overweight

$84 \quad$ Ibid at 796.

85 Ibid; JW Pierce \& J Wardle "Cause and Effect Beliefs and Self-esteem of Overweight Children" (1997) 38:6 Journal of Child Psychology and Psychiatry \& Allied Disciplines 645.

86 See Puhl \& Brownell, supra note 78 at 796; Phebe Cramer \& Tiffany Steinwert, "Thin is Good, Fat is Bad: How Early Does it Begin?” (1998) 19:3 Journal of Applied Development Psychology 429.

87 Lindsey Murtagh, "Judicial Interventions for Morbidly Obese Children" (2007) 35 JL Med \& Ethics 497 at 498.

88 UK Governmental Policy, see Ries \& Tigerstrom, supra note 12 at 370

89 See Ikeda, Crawford \& Woodward-Lopez, supra note 31 at 762. 
children do not see their own children as having weight problems. ${ }^{90}$ The combination of influencing the home and providing specific information to parents provides a basis to 'kick-start' parents into contributing to changes beneficial to improving the health and extending the life of their children. ${ }^{91}$ Each of these suggestions raises its own policy issues and these will be considered in full below.

\section{SCHOOL-BASED OBESITY POLICIES}

In this section, I will review the four main intervention approaches identified for schools, identifying some of the challenges regarding effectiveness and then considering the influence of homes and the impact on stigma. The four interventions examined are:

1. improving school food environments and encouraging healthy eating in schools;

2. introducing a nutritional curriculum and educating children on the methods and benefits of healthy eating;

3. promoting the increase of physical education programmes; and,

4. using surveillance mechanisms for recording the weight of children.

\section{A. Improving the Food Environment and Encouraging Healthy Eating in Schools}

The first potential policy involves moulding the school nutritional environment and promoting healthy eating by providing children access to good foods to assist them in making the good choices. In theory the policy appears a bit like a nudge achieved by limiting the availability of non-healthy alternatives. ${ }^{92}$ The types of interventions that could be used to improve school nutritional environments include food restrictions, limitations to food available in canteens and vending machines, fundraising, advertising, restricting the external food environment. Each of these types of interventions varies in their potential effectiveness.

Food restrictions and the regulation of food in canteens and vending machines are inherently related. Any restriction, especially ones involving the regulation of big food, is likely to face significant political opposition from large manufacturers. However the aim of protecting children, and the direct connection between this objective and measures proposed, provide a justification for regulation and will most likely be supported by the public. Regulation confined to the school environment makes it much less controversial: it represents regulation in a limited area, to a limited number of people. On this basis, when considering the improvement of the nutritional environment within schools, at a minimum, it should be possible to limit competitor foods within schools.

The implementation of Act 1220 in Arkansas ${ }^{93}$ demonstrates precedent for school-based regulatory measures. Act 1220 introduced legislation regulating lunches and imposing vending machine

90 Alan Jackson, "Why it's a parent's duty to tell their child they're FAT: An uncompromising warning from a top obesity expert" Daily Mail ( $9^{\text {h }}$ October 2013) online: <http://www.dailymail.co.uk/femail/article-2451475/Its-parents-duty-tellchild-theyre-FAT--Warning-obesity-expert.html>.

91 See Patel, supra note 16 at 173.

92 See Menard, supra note 56.

93 US, HB, 1220, An Act to Create a Child health Advisory Committee; To Coordinate Statewide Effortsto Combat Childhood Obeisity and Related Illnesses; To Improve the Health of Next Generation of Arkansans; And For Other Purposes, $84^{\text {th }}$ Assem, Reg Sess, Ark, 2003, (enacted); See Larson, supra note 24 at 3. 
restrictions. It also created a "Child Health Advisory Committee consisting of fifteen representatives from a variety of state public health, medical and educational organisations." ${ }^{" 44}$ The impact of the Act involves comprehensive measures of food regulation, including the creation of district advisory committees made up of parents, students, teaches, food service personal and officials, ${ }^{95}$ with the mandate of integrating nutrition and exercise into the national curriculum. ${ }^{96}$ Research considering Act 1220 was found that people in "Arkansas have an increased awareness of the association between childhood obesity and its associated health problems, as well as an increased knowledge that overweight children were more likely to become overweight adults." ${ }^{.97}$

Research further demonstrated that between the implementation of the Act in 2003 and 2006, the obesity baseline reduced from $20.9 \%$ to $20.4 \% .{ }^{98}$ Although this is only a slight decrease, the significance of curtailing the increase of obesity and trend towards a reduction in its prevalence is key. Parts of the Act 1220 focused on trans-fats ${ }^{99}$ and the regulation of vending machines ${ }^{100}$ this demonstrates the types of interventions required to result in a positive trend.

Restrictions on nutritional environment within schools are less likely to face significant public resistance and are much more likely to be deemed constitutional if they were challenged than blanket restrictions on similar foods in areas surrounding schools or in homes. Attempts to restrict the availability of certain kinds of foods (e.g., junk food or fast food) beyond the boundary of a school becomes extremely problematic, and is likely to face considerable opposition. Restrictions within schools, in contrast, only regulate access to foods by a limited number of vulnerable people who have limited spending power.

Other potential interventions to shape a school's nutritional environment include limiting the availability of unhealthy foods. For example, this might involve restricting vending machines, limiting the types of foods that can be brought in school lunchboxes, or by banning the advertisement of programmes that promote unhealthy foods. While lunchbox regulation may seem draconian, such regulation is already common in the school environment. Many schools already regulate children's lunches for allergens such as nuts. ${ }^{101}$ Given that food restriction policies already exist for specific food groups, it is possible to expand these restrictions to cover unhealthy foods.

In terms of advertisement and encouraging access to good foods it is beneficial and achievable to investigate the expansion of 'Breakfast for Learning, ${ }^{102}$ a Canadian national charity that focuses on school based nutritional programs. The charity aims to ensure that Canadian children are sufficiently nourished. It also provides support and equipment grants to schools to ensure that they have the tools

\footnotetext{
94 Ibid.

95 Ibid.

96 Ibid

97 Ibid; Fay W Boozman, College of Public Health, Year Three Evaluation: Arkansas Act 1220 of 2003 to Combat Childhood Obseity (2006) online: <http://www.uams.edu/coph/reports/2006Act1220_Year3.pdf >.

98 See Larson, supra note 24 at 4.

99 Healthy Food For Healthy Schools Act, SO 2008, c 2 at s 318 as amending the Education Act, RSO 1990 c E-2.

100 Ibid at s 319.

101 Eat Right Ontario, "Food allergies/intolerances”, online: Eat Right Ontario $<$ http://www.eatrightontario.ca/en/Articles/Food-allergies-intolerances/Peanut-free-Lunches-andSnacks.aspx\#.Upz6XZF9Ets>.

102 Breakfast For Learning, "Our impact”, online: Breakfast for Learning $<$ http://www.breakfastforlearning.ca/>.
} 
and resources necessary to provide sustainable breakfast, lunch and snack programmes. Assisting schools in becoming self-sustaining in the provision of good nutrition can greatly assist the campaign against childhood obesity. Given the pre-existence of initiatives, expansion should be possible if sufficient funding is made available. Initiatives of this kind should focus on ensuring that children receive sufficient and good nutrition, with the aim of teaching the dangers of and providing children with an alternative to unhealthy foods.

A significant benefit of interventions based on the improvement of a child's nutritional environment is its subtle appearance to the children involved: by changing the availability of food, the focus of any change becomes the food available and the healthier options. An added benefit is that by focusing on the food available, attention is drawn away from the children that already suffer from stigma resulting from their weight. This attention shift does not occur in measures aimed at reducing weight or exercise where the focus remains squarely on overweight individuals.

\section{B. Education Intervention and Provincial Curricula}

The aim of any educational focus intervention is the dissemination of the healthy eating message. Schools are an ideal forum within which to educate children about the rights and wrongs of healthy eating. Educational mechanisms are inherent and consistent with the function of schools. Schools already facilitate the teaching of other 'life-skills' classes, such as sexual education. ${ }^{103}$ The expansion of such classes to include lessons on health eating, exercise and healthy living can easily be incorporated as part of the Ontario Elementary Curriculum. ${ }^{104}$ School-based educational programmes encourage discussion amongst children, helping them to understand and potentially influence their home food environment.

The mechanism by which healthy eating classes can be introduced can include syllabus sections governing the importance of eating fresh foods, safe preparation of foods, classification of potential food groups, the benefits and appropriate portions of each food group and advice about overall daily intake of food. It is conceivable that there will be concerns that some teachers do not serve as the best role models for informing students about healthy eating. Such a concern equally applies to other life-skills classes, yet such classes are still perceived to be of benefit to students. Encouraging healthy eating in schools provides an intervention solution that has limited intrusiveness, is achievable, and has promise of being effective. There is significant precedent for the implementation of polices such as provincial curriculums. ${ }^{105}$ To children, schools are the primary learning environment: it is especially true for younger children that when they are attending school, they expect to learn and thus are open minded to learning when in the school environment. On this basis, schools provide a unique opportunity to educate on a large scale without significant intrusiveness.

Similar to healthy eating programmes, the focus of this type of measure is on educating children and focusing on the benefits of good food. In these instances, the emphasis should be taken away from classifications such as "overweight" and "obesity" and focus should be directed towards promoting good

\footnotetext{
103 Ontario Ministry of Education, "The Ontario Curriculum: Elementary", online: Ontario Ministry of Education $<$ http://www.edu.gov.on.ca/eng/curriculum/elementary/>.

104 Ibid.

105 Ibid.
} 
health. Unlike some of the other types of programmes, education programmes can be seen as reducing stigma.

Furthermore, a potential impact of using education in this manner is the indirect ability to promote healthy eating within the home. As children learn more about how to eat healthier and the benefits of healthy eating, they are likely to report or implement these lessons in their home environment. While not all homes will be responsive toward such information, it is an unobtrusive and potentially effective mechanism of promoting the dissemination of healthy eating. Striking the right balance may offer an unparalleled opportunity to help to shift Canadian perspectives on obesity and gain some traction towards creating a full cultural shift.

\section{Exercise Programmes}

Exercise is often seen as a potential method for weight loss and while it is appreciated that benefits of exercise to address obesity may be questionable in adults, ${ }^{106}$ there is evidence showing the usefulness of exercise in tackling childhood obesity. ${ }^{107}$ Children today are becoming 'increasingly sedimentary, ${ }^{108}$ and in 2000, 4 out of every 5 Canadian youths failed to meet international exercise guidelines for optimal growth and development. ${ }^{109}$ Given that obesity rates are so high and that exercise rates are so low, any potential intervention should consider the role of exercise.

An example of such an intervention could be the inclusion of exercise as a mandatory part of the curriculum. As with education programmes, the school environment is extremely useful for curriculumbased interventions. For instance, schools can be compelled to provide recess and/or the school environment can provide a basis for a community driven exercise programmes. Given that breaks are a necessary part of the school day, it seems strange not to ensure that during such a time children are obtaining some of their daily-required exercise. Canadian schools could very easily embrace the dual beneficial effect of encouraging exercise and providing a break from the classroom. Alternatively, students could be required to take part in a certain level of physical activity.

School-based promotion of exercise was included in Act 1220, which implemented significant changes to the physical education schemes of all public schools. A specific aim of Act 1220's advisory committees was the promotion of exercise and the integration of exercise into the curriculum. Such legislation provides a useful example of how schools can form the basis of exercise programmes. A local approach allows schools and district officials to collaborate in creating school-based and community-based exercise programmes. Collaboration with district officials opens the door to discussions regarding school financial concerns facilitating requests for additional funding in pursuit of physical education.

106 See Bogart, supra note 13.

107 Susi Kriemler et al, "Effect of School Based Physical Activity Programme (KISS) on Fitness and Adiposity in Primary Schoolchildren: Cluster Randomized Controlled Trial” (2010) 340:785 BMJ 1 at 7.

108 See WHO Website, supra note 14.

109 Alberta Education, Daily Physical Activity Handbook (Edmonton: Alberta Education, 2006) at section 1: Introduction at 2. 
Nonetheless there are some specific restrictions on this use of exercise policies, including the lack of resources, risks of liability, lack of parental support and risk of increased stigma. Participation in exercise, particularly organized sports (requiring equipment) can be extremely expensive. ${ }^{110}$

Of a particular concern for schools is the risk of liability if children get hurt. ${ }^{111}$ Much of this results from case law surrounding the standard of care owed by teachers or coaching staff. On a prima facie analysis it appears that the standard of care owed by coaching staff should, as members of a school's staff, owe the duty to act as a reasonable parent. However, there is significant jurisprudence suggesting, correctly, that coaches should be held to a higher standard. A more stringent standard of care was originally considered in the case of Thornton ${ }^{112}$ were Carrothers JA held that coaches, by virtue of "supra-parental expertise," 113 , were under a more stringent duty than that of a reasonable parent. This case involved the participation of a 15-year-old boy in a gymnastics class where he suffered a catastrophic spinal injury while attempting summersaults. The injury resulted in quadriplegia requiring care for the remainder of the boy's life. The court held that the coach knew or ought to have known, especially after another student suffered a broken wrist in the course of summersaults, of an inherent danger. ${ }^{114}$ Nonetheless, the coach had left the students unsupervised, had only provided two-inch thick mats as protection against falling and failed to warn the class of the dangers of the activity. The court held that the coach failed to supervise or provide adequate supervision and should have known better. Appreciating that coaches have specific expertise, Carrothers JA provided an outline of when a coach or specialist gym teacher would not be liable for allowing a dangerous activity: ${ }^{115}$

a) If the activity is suitable to the participant's age and mental and physical condition.

b) If the participant is progressively trained and coached to conduct the activity properly and to avoid danger.

c) If the equipment is adequately and suitably arranged.

d) If performance, having regard to its inherently dangerous nature, is properly supervised.

The coach in Thornton had expertise to teach gymnastics yet he failed to train students, to suitably arrange equipment or to adequately supervise.

The existence of legal principles, such as vicarious liability, raise legitimate concerns for the governing bodies of schools. While it should not be a barrier, the potential for large damages awards is palatable. Expensive personal injury claims are a significant factor influencing how school boards and governing councils balance already tight budgets.

110 Morgan Campbell, "Sportonomics: Will the cost of hockey diminish Canada's dominance?, Toronto Star (24 February2014), online: $<$ http://www.thestar.com/business/2014/02/24/sportonomics_will_the_cost_of_hockey_diminish_canadas_dominance.html>.

111 Child injured himself during a gymnastics class - Thornton et al v. Board of School Trustees of School District No 57 (Prince George), 73 DLR (3d) 35 (BCCA), [1976] BCJ No 1390 (QL).

112 Thornton v School District No. 57 (Prince George), [1978] 2 SCR 267, [1978] 1 WWR 607.

113 Ibid at para 20.

114 Thornton v School District No. 57 (Prince George) [1976] 5 WWR 240, (1976) 73 DLR (3d) 35 (BCCA) at 57

115 Ibid at 58 
Furthermore and worryingly, in recent years there has been a decrease in the availability of exercise programmes and recesses in schools in pursuit of "maximizing the amount of time spend studying substantive coursework." 116 In an increasingly results-orientated world, it is understandable that schools have taken this approach, however, research shows that the "rate of academic learning per unit of class time is enhanced by physically active students" ${ }^{\prime 17}$. Focusing on other aspects of the curriculum does not provide a suitable excuse for failing to provide physical education. In fact, the Californian-based SPARK programme promotes the integration of exercise within a "coordinated package of curriculum" 118 and focuses on providing schools with the necessary teaching skills to facilitate alignment with US National Association of Health, Physical Education, Recreation and Dance standards. ${ }^{119}$ SPARK focuses on elementary schools, and includes the provision of numerous afterschool activities to promote "physical activity while building a foundation for a healthy lifestyle" ${ }^{20}$. SPARK claims that using exercise in this manner has beneficial effects improving the success of students inside and outside of the classroom, while tackling the obesity problem. ${ }^{21}$ SPARK is useful to this discussion because it provides evidence of the expansive potential of schools in achieving the promotion of exercise. If schools could forgo any concerns about potential liability the introduction of educational programmes could be highly beneficial.

Finally, in relation to concerns about stigma, mandated exercise programmes may only serve to further exacerbate the issue. Any mandated exercise programme is likely to result in the identification of heavier individuals who are less physically capable. This could occur in the context of team sports, where an overweight child might be selected last or seen as incapable of making a positive contribution, or in the context of individual sports that involve significant running, creating an artificial isolation by ranking in relation to where they finish in any given race. For instance, if a heavier child comes tenth in a race of ten people, the other nine racers have the opportunity to watch the heavier child finish. Such a singling out of individuals will only serve to exacerbate pre-existing stigmatization.

\section{Surveillance}

Bearing in mind our proposed goal of prevention, weight surveillance tools should nevertheless be considered. The most effective method of prevention is to note when a trend is starting and stopping it before the trend escalates. The same goes for tackling overweight and obesity. By identifying those individuals whose weight is moving in the direction of overweight, specific measures may be implemented that can help that person. There are a number of ways of surveying the weight of school children. The most obvious is simply to measure weights, but such a measurement fails to take account of the extreme variations in the development of children, including differences in sex, height and

\footnotetext{
116 See Larson, supra note 24 at 2.

117 See Daily Physical Activity Handbook, supra note 109 at 3.

118 SPARK, 10 things to know about SPARK', online: SPARK <http://www.sparkpe.org/about-us/10-things-to-know-aboutspark/>.

119 Ibid.

120 Education Drive, "New Afterschool Physical Activity Program Engages Youth to Lead Active\& Healthy Lives" (11 March 2013), online: Education Drive <http://www.educationdive.com/press-release/20130311-new-afterschoolphysical-activity-program-engages-youth-to-lead-active-he/>.

121 See SPARK, supra note 117.
} 
build. ${ }^{122}$ Alternative weight measurements include simple weight measurement or extensive body fat testing.

A key element to successful school-based obesity programmes is not only to teach children good nutritional and exercise habits but to also promote weight monitoring. While weight monitoring is controversial, it serves the valuable purpose of informing children and parents of potentially dangerous trends in weight gain or loss. ${ }^{123}$ It also allows policy makers to track the impacts of contemporaneous measures. Act 1220 provides for annual BMI testing and since its implementation there have been improvements in obesity rates. ${ }^{124}$ BMI-testing may be contributing to the success seen in Arkansas. Tennessee also passed legislation, allowing schools to conduct student weigh-ins ${ }^{125}$ and the UK has introduced the National Children Measurement Programme requiring all children to be weighed at the age of 5 and at age $10 .{ }^{126}$ Each of these examples provides precedent for introducing similar weightmonitoring programmes in Canada. Such a policy can work in cohesion with home-based interventions, with the use of BMI report cards to help inform parents of how the weights of their children are trending in the wrong direction. Keeping the information transfer between homes and schools open through this pathway allows the prevention of overweightness and obesity from an extremely early stage, before the number of fat cells increases to an unmanageable rate.

There are two main concerns about promoting a policy that focus on weight-surveillance. The first relates to the unreliability of tests such as BMI monitoring. The second relates to the danger of increasing stigmatization of heavier children. ${ }^{127}$ BMI-measuring has the potential for errors: all measures must account for the varying development of different children. However, many of these concerns can be overcome by using the CDC's gender specific BMI-for-age growth charts, calculating a child's BMI into a percentile for that child's sex and age. ${ }^{128}$ By considering children in comparison to the national average, many concerns regarding the suitability of BMI can be limited.

There are also concerns that weight monitoring risks, particularly in girls, an exacerbation of stigmatization. ${ }^{129}$ Children face health risks associated with obesity along with social-ridicule. Ikeda recognizes that "young girls who perceive themselves as overweight or who actually have heavier weights are particularly vulnerable to low self-esteem."130 Decreased self-esteem and body dissatisfaction can greatly impact an individual's productivity, social interaction, and are "potent risk factors for the onset of eating disorders." ${ }^{" 131}$ A danger of focusing on surveillance is the risk that the

122 Carol Soto \& Jane White, "School Health Initiatives and Childhood Obesity: BMI Screening and Reporting" (2010) 11:2 Policy, Politics \& Nursing Practice at 110.

123 Proper nutrition may be found to help resolve other dietary problems such as anorexia.

124 See Larson, supra note 24 at $3 / 4$.

125 Ikeda, Crawford \& Woodward-Lopez, supra note 31 at 762.

126 Health \& Social Care Information Centre, National child measurement programme', online: HSCIC

$<$ http://hscic.gov.uk $>$; Note that the usefulness of this programme is limited by virtue of its voluntary participation, concerned parents can opt-out.

127 See Soto \& White, supra 122 at 110.

128 Centers for Disease Control, "About BMI for Children and Teens" (September 2011), online: CDC $<$ http://www.cdc.gov/healthyweight/assessing/bmi/childrens_bmi/about_childrens_bmi.html\#How\%20is\%20BMI\%20us ed\%20with\%20children $\% 20$ and $\% 20$ teens $>$.

129 See Alberta Handbook, supra at note 108 at 5 .

130 See Ikeda, Crawford \& Woodward-Lopez, supra note 31 at 766.

131 Ibid. 
problem will become refocused towards placing blame on the children personally. As explained, reflecting that children often have limited control over their nutritional environments and on the potential consequences of increased stigma, such policies are highly contentious.

Encouragingly, when Act 1220 implemented its programmes of weight monitoring, there was no measurable increase in teasing. ${ }^{132}$ On this basis, it might possible to conduct weight monitoring in a manner that is stigmatization-conscious. Soto and White recognize the importance of nurses in achieving this goal of BMI screening and reporting; they argue that the role of nurses should include "developing and implementing sensitive BMI screening and reporting programs. ${ }^{, 133}$ Moreover, they recognize issues of stigmatization as a significant consequence of obesity and argue for an active role for all school health professionals and guidance counselors. ${ }^{134}$ Soto and White may appreciate what is required, namely sufficient support structures, which if implemented properly can help to limit stigmatization. It is easy to argue that weight monitoring will lead to increased stigmatization however; individuals face stigmatization as a consequence of obesity and not weight monitoring. However, the provision of such support structures are undoubtedly expensive and fail to take into account the prevalence of weightrelated stigma within the medical profession.

\section{RECOMMENDING A POLICY THAT PREVENTS OBESITY BUT IS COGENT OF OBESITY STIGMA}

When reflecting upon the interventions we have discussed, the potential impact of increased stigma cannot be understated. Wiley provides a key insight into the importance of reducing stigma as "anti-fat stigma itself may contribute to poor health outcomes." ${ }^{, 135}$ She identifies the importance of framing the problems not in the terms of a child's weight but rather in terms of the good health. ${ }^{136}$ Wiley talks about the need for this paradigm shift, ${ }^{137}$ this assertion helps to emphasize the importance of focusing on obesity prevention rather than some of the other legitimate goals furthered by obesity interventions. On this basis, it seems that the most appropriate types of intervention for our proposed aims are healthy eating and education. The overall benefit achieved is the promotion of good and healthy eating and education on how to eat properly resulting in a preventative benefit.

\section{CONCLUSION}

In conclusion, the childhood obesity epidemic is a problem that needs to be rectified immediately. This discussion began by contextualizing obesity and defining it as a medical and psychosocial problem. Identifying schools as a more appropriate forum for intervention as opposed to regulating the nutritional environments in the homes or for big food. Recognizing the importance for facilitating a cultural

132 Laura Leviton, 'Children's Healthy Weight and the School Environment' (2008) 615:1 Annals of the American Academy of Political and Social Science 38 at 40.

133 See Soto \& White, supra note 122 at 112.

134 Ibid at 114

135 See Wiley, supra note 8 at 98.

136 Ibid.

137 Ibid. 
paradigm shift away from the current anti-fat prejudices, I focused on analyzing each potential intervention through the lens of stigma. On this basis, I proposed that the most effective methods for legal interventions in schools aimed at tackling obesity are healthy eating programmes and increased education. 